\title{
O PAPEL DOS MESTRADOS PROFISSIONAIS NA ÁREA \\ DE PlaneJamento URBano \\ E REGIONAL
}

\author{
Rosélia Piquet \\ Rodrigo Machado Vilani
}

\begin{abstract}
RESUMO O presente artigo tem por objetivo apresentar os desafios e as contribuiçóes da consolidação dos mestrados profissionais na pós-graduaçāo brasileira. Apesar dessa modalidade estar prevista desde a idealização da pós-graduação na década de 1950, a implementação de mestrados para a formação profissional no Brasil sofreu críticas ao longo de sua implantaçấo. A pesquisa analisa as normas da CAPES relacionadas ao reconhecimento dos mestrados profissionais e dos dados de sua evolução a partir de 2000, particularmente, da área de Planejamento Urbano e Regional. À guisa de conclusão são tecidas consideraçōes gerais e específicas quanto à importância dos mestrados profissionais no âmbito da pós-graduaçāo nacional, formando profissionais qualificados para realizar uma leitura adequada e propor medidas positivas para a construção de uma sociedade justa e igualitária para as presentes e futuras geraçôes.
\end{abstract}

P A L A V R A S - C H A V E Mestrados profissionais. Planejamento Urbano e Regional. Capes. Qualificação profissional.

\section{A POLÊMICA QUANTO AOS MESTRADOS PROFISSIONAIS}

Em 1995, quando a Portaria de no 47 determinou "a implantação na Capes de procedimentos apropriados à recomendação, acompanhamento e avaliação de cursos de mestrados dirigidos à formação profissional" a resposta do meio acadêmico foi de perplexidade: algumas áreas permaneceram reticentes; outras, francamente hostis. Entretanto, a proposta de implantação de cursos de mestrado voltados à qualificaçáo profissional encontra-se presente no sistema de Pós-Graduação brasileiro desde a sua concepção original nos anos de 1950.

A proposta de montagem de um sistema capaz de corrigir as deficiências qualitativas e quantitativas na formação de quadros superiores emerge em um período de grande efervescência administrativa e institucional do país, pois se tratava, nos termos da época, de reaparelhar o Estado dotando-o de uma diversidade de órgãos e instrumentos que regulassem e permitissem a intervenção nos diferentes aspectos da vida nacional que atravessava então profundas alteraçôes em seu sistema produtivo e em sua estrutura social.

Os dados do Censo de 1950 de fato tornaram evidentes grandes mudanças quando comparados aos de 1940, revelando uma acentuada transferência da mão-de-obra para os setores secundário e terciário da economia e um acelerado aumento da migração populacional do Nordeste para o Centro-Sul. O contingente de profissionais de 
1 CÓRDOVA, Rogério de Andrade. A brisa dos anos cinqüenta: a origem da Capes. Apud Boletim Infocapes, comemorativo dos 45 anos, 1997.
2 Resolução n. 1/95 do Conselho Superior da Capes, com base no documento "Programa de Flexibilização do Modelo de Pós-Graduação, senso estrito, em nível de mestrado". nível superior correspondia a $0,7 \%$ da massa da população economicamente ativa, atingindo em valores absolutos 132.035 profissionais. Segundo diagnóstico do então Ministro da Educação, Simōes Filho (apud Córdova, 1997¹),

(...) urgia estimular a expansão do Ensino Superior e fazê-lo segundo novos paradigmas de qualidade, pois não se dispunha de gente capacitada para os postos em que se exigem conhecimento e técnicas, indispensáveis ao tipo atual de sociedade, eminentemente industrial e técnico [e, ainda,]

o primado das letras sobre as ciências, que foi um dos males de nossa formação cultural, precisa ser corrigido nas suas consequências atuais, sendo necessário promover a formaçáo de especialistas como economistas, técnicos em finanças, estatísticos, pesquisadores sociais visando a obtenção de tripulaçóes para novas unidades, não só de empreendimentos governamentais, como também da iniciativa privada.

Assim, em 11 de julho de 1951, pelo Decreto n. 29.741, da Presidência da República, é instituída uma Comissão para promover a Campanha Nacional de Aperfeiçoamento de Pessoal de Nivel Superior - CAPES, que surge simultaneamente a outros órgãos e agências que tiveram - e muitos deles ainda têm - importante presença na vida nacional, tais como a Comissão Nacional de Política Agrária, a Comissão Nacional de Alimentação, o Conselho Nacional de Pesquisas - CNPq, o Banco Nacional de Desenvolvimento Econômico BNDE, a Companhia de Petróleo Brasileiro - Petrobras.

A CAPES é então estruturada com apenas dois programas: o Programa Universitário visando o desenvolvimento das universidades e institutos de ensino superior e o Programa de Quadros Técnicos e Científicos, para atender à demanda de pessoal de nivel superior por parte dos meios profissionais e culturais do país.

Pelo exposto, vê-se que, em sua origem, a capacitação de quadros profissionais mereceu a mesma atenção que a formaçáo de quadros universitários. É nas décadas de 1960 e, principalmente na de 1970, que essa orientação se altera e o Governo brasileiro passa a investir maciçamente na formação de profissionais de maior poder multiplicador - os professores do ensino superior - para garantir a formação dos quadros de docentes e pesquisadores, essenciais para a expansão do próprio sistema e para a promoção da pesquisa científica e tecnológica no País.

A partir de então, o crescimento da pós-graduação no Brasil baseia-se em cursos de mestrado que se caracterizam predominantemente como o primeiro degrau para a qualificação acadêmico-científica necessária à carreira universitária, caracterizando-se também como etapa preliminar na obtenção do grau de Doutor. Contudo, passaram a surgir iniciativas de oferta de mestrados dirigidos à formação de profissionais, muitas vezes em resposta direta a demandas de agências e empresas, interessadas na qualificação de seus quadros e, a partir da década de 1990, fatores relacionados com as profundas transformaçóes observadas no Brasil e no mundo - globalização da economia, modernização dos sistemas de produção, aumento da competitividade internacional - determinaram uma crescente demanda por profissionais com perfil de qualificação especializada e náo voltada para a pesquisa acadêmica. Assim, e ainda segundo a CAPES em documento de 1995, a qualificação acadêmico-científica, ao contrário do que se pensava na década de 1960, "não é mais suficiente para também assegurar a formação de pessoal de alta qualificação para atuar nas áreas profissionais, nos institutos tecnológicos e nos laboratórios industriais." ${ }^{2}$ 
Sob essa perspectiva, ressalte-se, em relação aos Mestrados Profissionais (MP), "a ênfase na adição de valor social ao mercado de trabalho e à comunidade em geral, focando a profissionalização e gestão das mais diversas formas de atividades sociais, empresariais, tecnológicas e até culturais" (Silveira; Pinto, 2005, p. 39).

Observa-se, portanto, que a proposta de implantação de cursos de mestrado voltados para a qualificaçáo profissional, inicialmente designados de mestrados profissionalizantes (só um pouco mais tarde passam a ser chamados de mestrados profissionais), apenas ativou o que estava latente no sistema desde sua concepção original. Cabe registrar que a pós-graduação lato sensu foi deixada de lado pela política de educação superior brasileira uma vez que permaneceu fora dos critérios de avaliação da Capes, ao contrário dos cursos stricto sensu, de mestrado e doutorado, que sáo sistematicamente avaliados. Tal fato deu margem à multiplicação desses cursos de modo indiscriminado, não assegurando nenhuma garantia da qualidade ao profissional que neles busca aperfeiçoamento, atualização ou especialização em campos específicos.

Por que então a polêmica em relaçáo aos mestrados profissionais (MP) - cuja existência legal decorre da portaria da Capes, no 80 de novembro de 1998 -, se o objetivo de sua implantaçáo seria o de atender à demanda do profissional que busca um aperfeiçoamento além da graduação, sem a intenção de adentrar na carreira acadêmica?

Parte da resistência de algumas áreas acadêmicas aos MP se origina na identificação desses com interesses que seriam das empresas (RIBEIRO, 2005) e, desse modo, que a pesquisa acadêmica se tornaria subalterna aos interesses do capital. Sob essa visão os MP estariam voltados ao mundo da produção, sem discussão de quem se beneficiaria com os ganhos de produtividade: o usuário, o trabalhador ou os donos do capital.

Outros especialistas chegaram mesmo a assumir uma posição radical, como é o caso de Moura Castro (2006) ao afirmar que "ainda há adversários ferrenhos, sejam por purismo ou por defenderem reservas de mercados".

Diante dos questionamentos sobre essa modalidade de curso, o Conselho Técnico Científico da Capes em sua 50a reunião, de setembro de 1999, explicita que a criaçáo do Mestrado Profissionalizante responde a uma necessidade socialmente definida de capacitação profissional de natureza diferente da propiciada pelo Mestrado Acadêmico, tendo o mesmo nível de formação e padrão de qualidade equivalentes. Buscando dirimir as dúvidas então existentes, o site da Capes passa a conter uma clara definição sobre os mestrados profissionais:

o Mestrado Profissional é a designação do mestrado que enfatiza estudos e técnicas diretamente voltadas ao desempenho de um alto nível de qualificação profissional. Esta ênfase é a única diferença em relação ao acadêmico. Confere, pois, idênticos grau e prerrogativas, inclusive para o exercício da docência, e, como todo programa de pós-graduação stricto sensu, tem a validade nacional do diploma condicionada ao reconhecimento prévio do curso (Parecer CNE/CES 0079/2002.

Um Mestrado Profissional deve ter padróes de exigências tão rigorosos quanto os do mestrado acadêmico, só que com critérios diferentes, posto que são cursos de natureza qualitativamente diferentes. Enquanto no mestrado acadêmico pretende-se, a longo prazo, formar pesquisadores, no profissional o que se espera é que ocorra uma imersão na pesquisa, mas não que o titulado se torne um pesquisador. O objetivo é formar profissionais capazes de utilizar e localizar a pesquisa no exercício de sua profis- 
3 Em 2011, segundo dados do GEOCAPES, havia um total de 3.128 programas de pósgraduação, sendo: a) Mestrado: 1.175 ; b) Doutorado: 52; c) Mestrado/doutorado: 1.563 ; d) Mestrado profissional: 338 .

O P A P E L D O S M E S T R A D O S P R O F I S S I O N A I S

são. Esse é um desafio nada trivial - a articulação entre a prática e a teoria que alicerça essa prática. Daí ser necessário que a maior parte dos docentes dos MP tenham doutorado e mantenham produção científica constante, devidamente avalizada. $\mathrm{O}$ aluno de um MP náo está sendo treinado ou informado, ele está sendo formado. O que se pretende é uma mudança de qualidade do aluno.

No mundo atual, que requer formação mais qualificada, a tendência é termos cada vez mais uma demanda de mestres e doutores além da academia, como indica pesquisa de Veloso (2004) de que dois terços dos mestres e um terço de doutores encaminha-se para destinos que não são os do ensino superior.

A oferta dessa modalidade de curso vem assumindo lugar crescentemente maior na pós-graduação brasileira e hoje são poucos os redutos de resistência a essa modalidade, que hoje representa cerca de $10,8 \%$ do total de programas de pós-graduação 3 .

Nos Quadros 1a e 1b sáo mostrados, respectivamente, os números do crescimento dos programas de MP em relaçáo aos mestrados acadêmicos por grande área e dos MP por região, indicando sua distribuição em todas as regiōes do país:

Quadro 1a - Mestrados profissionais e acadêmicos por grande área

\begin{tabular}{|c|c|c|c|c|c|c|c|c|}
\hline \multirow{3}{*}{ Grande Área } & \multicolumn{8}{|c|}{ Ano } \\
\hline & \multicolumn{2}{|c|}{2000} & \multicolumn{2}{|c|}{2005} & \multicolumn{2}{|c|}{2010} & \multicolumn{2}{|c|}{2012} \\
\hline & MD & MP & MD & MP & MD & MP & MD & MP \\
\hline Ciências Agrárias & 170 & 0 & 212 & 1 & 300 & 13 & 346 & 20 \\
\hline Ciências Biológicas & 143 & 1 & 180 & 7 & 226 & 8 & 258 & 15 \\
\hline Ciências da Saúde & 294 & 11 & 350 & 25 & 402 & 38 & 445 & 74 \\
\hline Ciências Exatas e da Terra & 170 & 4 & 211 & 6 & 257 & 10 & 274 & 14 \\
\hline Ciências Humanas & 195 & 1 & 284 & 5 & 392 & 6 & 451 & 19 \\
\hline Ciências Sociais Aplicadas & 131 & 7 & 217 & 33 & 306 & 50 & 342 & 70 \\
\hline Engenharias & 158 & 7 & 221 & 23 & 275 & 44 & 302 & 57 \\
\hline Linguística, Letras e Artes & 79 & 0 & 111 & 0 & 160 & 0 & 175 & 2 \\
\hline Multidisciplinar & 52 & 2 & 107 & 32 & 226 & 78 & 301 & 124 \\
\hline TOTAL & 1392 & 33 & 1893 & 132 & 2544 & 247 & 2894 & 395 \\
\hline
\end{tabular}

MD: mestrado acadêmico e programas que incluem mestrado acadêmico e doutorado; MP: mestrado profissional

Elaborado a partir de GEOCAPES (2012)

Quadro 1b - Evolução dos mestrados profissionais por região

\begin{tabular}{|l|c|c|c|c|}
\hline Regiáo & $\mathbf{2 0 0 0}$ & $\mathbf{2 0 0 5}$ & $\mathbf{2 0 1 0}$ & $\mathbf{2 0 1 2}$ \\
\hline Norte & 0 & 3 & 7 & 20 \\
\hline Nordeste & 2 & 20 & 41 & 70 \\
\hline Sudeste & 18 & 74 & 132 & 203 \\
\hline Sul & 8 & 25 & 51 & 79 \\
\hline Centro-Oeste & 5 & 10 & 16 & 23 \\
\hline Total & $\mathbf{3 3}$ & $\mathbf{1 3 2}$ & $\mathbf{2 4 7}$ & $\mathbf{3 9 5}$ \\
\hline
\end{tabular}

Elaborado a partir de GEOCAPES (2012). 
O aumento das Engenharias (Quadro 1a) vai ao encontro da necessidade constantemente alardeada da falta de profissionais da área para o desenvolvimento de grandes projetos no país (ver Agopyan; Oliveira, 2005). Contudo, o destaque vai para a Grande Área Multidisciplinar, criada com essa denominação em 1999 e que, em 2008, passou a ser designada área Interdisciplinar dentro da Grande Área Multidisciplinar (Portaria CAPES n ${ }^{\circ}$ 09, de 23 de Janeiro de 2008). Seu aumento significativo se deve, segundo o documento de área para o triênio 2007-2009, a dois fatores específicos. Primeiramente, a criação da comissão para a área "propiciou e induziu [...] a proposição de cursos em áreas inovadoras e interdisciplinares”. O segundo aspecto está relacionado à existência "de novos cursos de universidades mais jovens ou distantes, com estruturas de Pós-Graduação ainda em fase de formação e consolidação, com dificuldades naturais de constituir densidade docente para abrir cursos em áreas disciplinares tradicionais" (CAPES, 2008).

Exceto pela área de Linguística, Letras e Artes, os MP possuem programas em todas as demais grandes áreas da pós-graduação brasileira, contudo:

Não obstante essa diversidade, a identidade dos mestrados profissionais não está somente determinada pela sua área temática, mas, fundamentalmente, pelo enorme desafio de integrar com rigor a pesquisa no seu processo de desenvolvimento e conseguir a aplicabilidade dos resultados para transformar a realidade estudada (NEGRET, 2008, p. 218).

Os números (Quadro 1b) também confirmam a tendência de concentração na regiáo Sudeste, onde teve início a pós-graduação no Brasil, mas indicam uma expansão nas regiôes Nordeste e Sul. Ainda assim, por ser o centro econômico do país, a regiāo deve manter-se à frente nos programas de formação profissional, ainda que outras regiốes aumentem sua participação nessa modalidade.

\section{OS MESTRADOS PROFISSIONAIS EM PLANEJAMENTO URBANO E REGIONAL}

É nos anos 1970 que o planejamento governamental voltado às questôes urbanas e regionais assume no Brasil um elevado grau de institucionalidade, durante o auge dos governos militares, o que lhe confere caráter centralizador. É quando também a capacitação de pessoal na área começa a ganhar impulso e são entáo lançados os primeiros cursos de mestrado sobre planejamento urbano e regional na Universidade Federal do Rio Grande do Sul (1970), na Universidade Federal do Rio de Janeiro (1972), na Universidade Federal de Pernambuco (1975) e Universidade de Brasília. A Universidade Federal de Minas Gerais já havia criado em 1967 o Centro de Desenvolvimento e Planejamento Regional (Cedeplar), com a finalidade de abrigar um programa de pesquisa e ensino de pós-graduaçáo na área da Economia Regional.

Era de tal ordem a importância atribuída à formação de quadros para atuação no sistema de planejamento que a primeira turma do curso da UFRJ, entấo sob a responsabilidade da Coordenação dos Programas de Pós-graduação em Engenharia (COPPE), é destinada a técnicos do Banco Nacional de Habitação (BNH), do Serviço Federal de Habitação e Urbanismo (SERFHAU) e de órgãos do governo federal envolvidos com o planejamento urbano ou regional. 
Ao longo da década de 1980 as novas tendências na dinâmica socioeconômica mundial, configurando um novo cenário com significativas diferenças em relação ao período do pós-guerra, póem em cheque o planejamento, que em nosso país passa a ser recusado, posto que identificado com o autoritarismo, com o "olhar do burocrata". Assim, com o enfraquecimento do Estado, o planejamento cai em descrédito e os programas de pós-graduação, montados para a formação de pessoal na área, gradualmente se transformam de fato em programas de estudos urbanos e regionais, sendo sintomático que no período de quase 20 anos (entre 1975 e 1993) nenbum novo curso tenha sido proposto na área.

A partir dos anos 1990, a reduçáo da face produtiva do Estado e a tendência à adoção de políticas descentralizadoras tornam as instâncias subnacionais de governo atores mais relevantes na atuação do setor público. Neste cenário, caracterizado por diferentes dinâmicas sociais e de distribuição do poder entre atores sociais, a gestão e as políticas públicas tornam-se diferentes daquelas que imperavam na época do planejamento centralizado, o que impóe desafios diversos aos programas de formação de recursos humanos.

É, contudo, só a partir dos anos 2000, quando o país dá sinais de recuperação econômica com a retomada de vultosos investimentos em projetos estruturantes, que se volta a falar na premência de se pensar o longo prazo - o que implica na retomada do planejamento - e quando então novos cursos são propostos. Este seria também o momento ideal para se repensar o conteúdo dos programas formativos, de se redefinir o que neles se ensina e de se propor novos formatos de cursos mais voltados à análise das realidades regionais e locais. É então quando surgem as primeiras propostas de Mestrados Profissionais na área.

A análise a seguir desenvolvida é baseada nos registros da Capes referentes aos cursos da área de Planejamento Urbano e Regional e Demografia assim como nas informaçôes dos próprios Programas divulgadas na internet. A subárea de Demografia não tem até o momento nenhum curso na modalidade analisada, razão pela qual não é mencionada no texto.

Pelos dados do Quadro 2, vê-se que todos os mestrados profissionais foram propostos já nos anos 2000, sendo um credenciado ainda em 2001 e os demais somente a partir de 2007.

As universidades particulares predominam quanto à oferta na área de Planejamento Urbano e Regional, sendo responsáveis por cinco dos sete programas de Mestrado Profissional, o que caracteriza uma dependência administrativa diversa em relação aos programas acadêmicos, onde as universidades particulares têm presença modesta, com apenas oito dos vinte e quatro cursos existentes.

Se em seus primórdios os mestrados da área já poderiam ser vistos como cursos predominantemente voltados à prática profissional e não à reprodução da estrutura acadêmica, hoje essa direção se afirma mais ainda. Sem dúvida o Planejamento Urbano e Regional não se constitui em campo de conhecimento específico, mas sim em área de aplicaçáo de conhecimentos. O enfrentamento teórico e político das questóes dos anos 2000 requer avançar nas análises territoriais com pesquisas que busquem identificar a lógica de funcionamento dos vários circuitos de valorização do capital em seus vínculos com as condiçóes de vida da população. Para que seja reconhecida a dimensão deste desafio, convém destacar que, no país, como afirma Brandão (2011), "nunca as diversidades produtivas, sociais, culturais, espaciais (regionais, urbanas e rurais) foram usadas no sentido positivo. Foram tratadas sempre como desequilíbrios, assimetrias e problemas". 
Quadro 2 - Mestrados Profissionais recomendados pela CAPES na área de Planejamento Urbano e Regional - 2012

\begin{tabular}{|c|c|c|c|c|c|}
\hline \multicolumn{2}{|r|}{ Programa } & Instituição & D.A.* & Início & Conceito \\
\hline 1 & $\begin{array}{l}\text { Planejamento Regional e } \\
\text { Gestão da Cidade }\end{array}$ & $\begin{array}{l}\text { Universidade Candido Mendes } \\
\text { (UCAM) }\end{array}$ & Particular & 2001 & 4 \\
\hline 2 & $\begin{array}{l}\text { Desenvolvimento } \\
\text { Regional }\end{array}$ & Faculdade Alves Faria (ALFA) & Particular & 2007 & 3 \\
\hline 3 & $\begin{array}{l}\text { Planejamento } \\
\text { Ambiental }\end{array}$ & $\begin{array}{l}\text { Universidade Católica de } \\
\text { Salvador }\end{array}$ & Particular & 2007 & 3 \\
\hline 4 & $\begin{array}{l}\text { Planejamento Territorial } \\
\text { e Desenvolvimento } \\
\text { Sócio-Ambiental }\end{array}$ & $\begin{array}{l}\text { Universidade } \\
\text { do Estado de Santa } \\
\text { Catarina (UDESC) } \\
\end{array}$ & Estadual & 2007 & 3 \\
\hline 5 & $\begin{array}{l}\text { Políticas Sociais e Dinâmicas } \\
\text { Regionais }\end{array}$ & $\begin{array}{l}\text { Universidade Comunitária } \\
\text { da Região de Chapecó } \\
\text { (UNOCHAPECÓ) }\end{array}$ & Particular & 2010 & 3 \\
\hline 6 & $\begin{array}{l}\text { Planejamento e Governança } \\
\text { Pública }\end{array}$ & $\begin{array}{l}\text { Universidade Tecnológica } \\
\text { Federal do Paraná (UTFPR) }\end{array}$ & Federal & 2010 & 3 \\
\hline 7 & Desenvolvimento Regional & $\begin{array}{l}\text { Instituto de Ensino Superior e } \\
\text { Pesquisa (INESP) }\end{array}$ & Particular & 2011 & 3 \\
\hline
\end{tabular}

Fonte: Coordenação de Aperfeiçoamento de Pessoal de Nível Superior (CAPES). Disponível em: http://www. capes.gov.br/cursos-recomendados (Levantamento dos dados por Mariana Pessoa, mestranda do Programa em Planejamento Regional e Gestâo de Cidades) (*): dependência administrativa.

O autor alerta, portanto, para a necessidade de que sejam reconhecidas as potencialidades existentes na diversidade, o que implica na articulaçáo entre processos econômicos transescalares e no reconhecimento da história relativamente autônoma, de regióes e lugares (BRANDÃO, 2011). Questionar os interesses constituídos nos mais de cinco mil municípios, distribuídos numa grande variedade de contextos regionais, e estudar o papel exercido pelo agronegócio, pelo capital imobiliário e industrial, pelo capital financeiro e, pelas organizaçôes políticas e sociais nas mudanças territoriais são, sem dúvida, tarefas do presente.

A descentralização administrativa trouxe novas questôes relacionadas à procura de pessoal qualificado, sendo que a consolidação desse processo passou a exigir um melhor aparelhamento das administraçôes públicas locais, com o consequente aumento da demanda por profissionais para atuar em prefeituras e órgãos públicos em geral. Embora o planejamento, neste âmbito, se limite a ser em geral um esforço de coordenação administrativa, não atingindo o estágio da produção de efetivas mudanças estruturais, a ampliação de conhecimento sobre os processos econômicos, socioespaciais e culturais requer ação qualificada do corpo técnico envolvido nas tarefas administrativas. A carência de melhores e mais numerosas pesquisas sobre a diversidade regional e urbana brasileira vem encontrando resposta na ampliação da oferta de cursos na área, em conexão, inclusive, com a nova distribuição espacial dos investimentos públicos e privados no território nacional.

É sabida a carência de qualificação que domina os quadros da administração pública brasileira em municípios de pequeno porte e que sobrevivem graças aos repasses do Fundo de Participaçáo Municipal do Governo Federal. São comuns os relatos da existência de prefeitos que embora alfabetizados não têm competência de interpretar editais nem contam com pessoal técnico minimamente qualificado para tal e, com isso, perdem a oportunidade de levarem a seus municípios muitos dos repasses de programas especiais existentes nas esferas estadual e federal. 
Tendo em mente que o Brasil tem atualmente 5.560 municípios e se, por exemplo, cada um deles passasse a ter em seus quadros um mestre profissional na Secretaria de Saúde e de Educação, dando com isso um salto de qualidade na gestão dessas duas áreas decisivas no resgate de nossa dívida social, é possível aquilatar a magnitude do esforço de formação qualificada que se apresenta, mesmo que se atenda apenas a uma reduzida parcela desses municípios.

Assim, não é de surpreender que os mestrados profissionais em planejamento urbano e regional se localizem predominantemente no interior do país ou em metrópoles de segundo grau, conforme indicam os dados do Quadro 3.

Quadro 3 - Mestrados Profissionais e a população das cidades de localização

\begin{tabular}{|c|c|c|c|c|c|c|}
\hline Programa & $\begin{array}{l}\text { Instituição } \\
\text { SIGLA }\end{array}$ & Regiāo & $\begin{array}{l}\text { Cidade } \\
\text { UF }\end{array}$ & $\begin{array}{l}\text { População } \\
\text { (a) }\end{array}$ & $\begin{array}{l}\text { População com } \\
\text { nível superior } \\
\text { completo (b) }\end{array}$ & $\begin{array}{c}\% \\
\text { (b) } /(\mathrm{a})\end{array}$ \\
\hline $\begin{array}{l}\text { 1. Planejamento } \\
\text { Regional e Gestão } \\
\text { da Cidade }\end{array}$ & $\begin{array}{l}\text { Universidade } \\
\text { Candido Mendes } \\
\text { (UCAM) }\end{array}$ & Sudeste & $\begin{array}{c}\text { Campos } \\
\text { RJ }\end{array}$ & 463.731 & 31.658 & 6,8 \\
\hline $\begin{array}{l}\text { 2. Desenvolvimento } \\
\text { Regional }\end{array}$ & $\begin{array}{l}\text { Faculdades Alves } \\
\text { Faria } \\
\text { (ALFA) }\end{array}$ & $\begin{array}{l}\text { Centro } \\
\text { Oeste }\end{array}$ & $\begin{array}{c}\text { Goiânia } \\
\text { GO }\end{array}$ & 1.302 .001 & 177.697 & 13,6 \\
\hline $\begin{array}{l}\text { 3. Planejamento } \\
\text { Ambiental }\end{array}$ & $\begin{array}{l}\text { Universidade } \\
\text { Católica } \\
\text { de Salvador } \\
\text { (UCSAL) }\end{array}$ & Nordeste & $\begin{array}{l}\text { Salvador } \\
\text { BA }\end{array}$ & 2.675 .656 & 255.606 & 9,6 \\
\hline $\begin{array}{l}\text { 4. Planejamento } \\
\text { Territorial } \\
\text { e Desenvol. } \\
\text { Socioambiental }\end{array}$ & $\begin{array}{l}\text { Universidade do } \\
\text { Estado } \\
\text { de Santa Catarina } \\
\text { (UDESC) }\end{array}$ & Sul & $\begin{array}{l}\text { Florianópolis } \\
\text { SC }\end{array}$ & 421.240 & 90.436 & 21,5 \\
\hline $\begin{array}{l}\text { 5. Políticas Sociais } \\
\text { e Dinâmicas } \\
\text { Regionais }\end{array}$ & $\begin{array}{l}\text { Universidade } \\
\text { Comunitária } \\
\text { da Região de } \\
\text { Chapecó } \\
\text { (UNOCHAPECÓ) }\end{array}$ & Sul & $\begin{array}{c}\text { Chapecó } \\
\text { SC }\end{array}$ & 183.530 & 16.402 & 8,9 \\
\hline $\begin{array}{l}\text { 6. Planejamento } \\
\text { e Governança } \\
\text { Pública }\end{array}$ & $\begin{array}{l}\text { Universidade } \\
\text { Tecnológica Federal } \\
\text { do Paraná (UTFPR) }\end{array}$ & Sul & $\begin{array}{c}\text { Curitiba } \\
\text { PR }\end{array}$ & 1.751 .907 & 307.175 & 17,5 \\
\hline $\begin{array}{l}\text { 7. Desenvolvimento } \\
\text { Regional }\end{array}$ & $\begin{array}{l}\text { Instituto de Ensino } \\
\text { Superior e Pesquisa } \\
\text { (INESP) }\end{array}$ & Sudeste & $\begin{array}{l}\text { Divinópolis } \\
\text { MG }\end{array}$ & 213.016 & 18.494 & 8,7 \\
\hline
\end{tabular}

Fonte: Coordenação de Aperfeiçoamento de Pessoal de Nível Superior (CAPES). Disponível em: <http://www. capes.gov.br/cursos-recomendados $>$. (Levantamento dos dados por Mariana Pessoa, mestranda do Programa em Planejamento Regional e Gestão de Cidades)

A participação da população com grau superior, um dos indicadores que permite estimar o nível de capacitação de um lugar, é bastante diferenciada entre as cidades que abrigam esses cursos. As capitais apresentam um bom nível onde se destaca Florianópolis. Salvador configura uma exceção, aproximando-se das cidades de porte médio que também possuem percentual baixo de populaçáo com nível superior completo. Contudo, vê-se o quanto o país avançou na formaçáo universitária quando se compara os dados do presente aos níveis da década de 1940/50 referidos no primeiro item desse texto. Vê-se que na atualidade apenas a população com nível superior de Goiânia é superior ao total brasileiro de então. 
O Quadro 3 também indica que à exceção da Regiāo Norte todas as demais macrorregióes brasileiras têm cursos nessa modalidade, cabendo destaque para a Região Sul, o que provavelmente reflete a grande ênfase que vem sendo dada nos Estados de Santa Catarina e Paraná ao planejamento estadual.

Observe-se que apenas um leva no título a palavra "urbano". Contudo esse é um traço comum tanto nos mestrados profissionais quanto nos acadêmicos, sendo relacionado ao período de sua criação, pois nos cursos propostos após 2000 a referência ao urbano é quase inexistente, ocorrendo em apenas dois de um total de 30 programas. Tal fato indica uma mudança de foco da área, o que provavelmente corresponde ao reconhecimento dos desafios específicos quanto à necessidade de melhor se conhecer as regióes náo hegemônicas do país e, também, à nova dinâmica espacial da economia brasileira, pois as maiores regiôes metropolitanas vêm perdendo posiçấo relativa frente às cidades de porte médio e às metrópoles de segundo grau.

A formação dos docentes dos MP da área de Planejamento Urbano e Regional, cujos dados se encontram sintetizados no Quadro 4, se caracteriza não só por apresentar grande diversidade disciplinar, como também pelo fato de que cada docente obteve seus títulos de graduação, mestrado e doutorado em cursos de natureza diversa. Esse é um dado que merece registro, pois no momento a diretoria da Capes vem promovendo debates com o intuito de discutir a importância da interdisciplinaridade e da transdisciplinaridade na formação acadêmica para o mundo do século XXI.

A área de Planejamento Urbano e Regional ainda não realimenta a formação de seus quadros docentes, uma vez que apenas dois docentes de um total de 64 são egressos da própria área. Conforme se observa no Quadro 4, as áreas que predominam na formação docente da área são: Administração de Empresas, a graduação de maior representatividade, e Engenharia da Produção quanto aos graus de mestre e doutor.

Quadro 4 - Formação de Docentes

\begin{tabular}{|c|c|c|c|}
\hline \multirow{2}{*}{ Nome do Curso } & \multicolumn{3}{|c|}{ Nível } \\
\hline & Graduação & Mestrado & Doutorado \\
\hline Administração de Empresas & 11 & 8 & 5 \\
\hline Economia & 10 & 2 & 6 \\
\hline Engenharia da Produção & 3 & 9 & 11 \\
\hline Geografia & 7 & 5 & 8 \\
\hline Ciências Sociais & 6 & 2 & 2 \\
\hline Planejamento Urbano e Regional & - & 2 & 2 \\
\hline Arquitetura e Urbanismo & 3 & 3 & 1 \\
\hline Direito & 3 & 3 & 1 \\
\hline Demografia & - & 1 & 2 \\
\hline Outros cursos* & 19 & 21 & 19 \\
\hline \multicolumn{4}{|c|}{$\begin{array}{l}\text { *Diante da grande diversidade das demais formaçóes (com representaçóes de um a dois profes- } \\
\text { sores) optou-se por agrupá-las em "Outros Cursos", sendo exemplos: Sociologia, Antropologia, } \\
\text { Serviço Social, História, Agronomia, Ciências Biológicas, Biologia, Meio Ambiente, Psicologia, } \\
\text { Enfermagem e outros. (Dados obtidos nos sites dos Programas) }\end{array}$} \\
\hline
\end{tabular}


Com base nas informações que constam nos sites dos Programas é possível afirmar que a oferta de disciplinas do conjunto dos MP indica claramente que são cursos voltados à análise de suas próprias regióes, sendo que apenas em um deles é ministrada disciplina sobre o desenvolvimento brasileiro. Em contra partida são oferecidas 16 disciplinas de Instrumentos de Análise Regional. Surpreende a baixa oferta de disciplinas sobre as questóes das administraçóes locais, pois em apenas um Programa essa disciplina é obrigatória e em três outros consta como eletiva.

Embora a oferta de disciplinas teóricas, 18 no total dos Programas, possa ser considerada elevada, apenas cinco são elencadas como obrigatórias. Coerentemente com os títulos dos Programas, apenas dois registram disciplinas especificamente voltadas para a análise do fenômeno urbano. As disciplinas de caráter metodológico geral constam da estrutura curricular de seis Programas, enquanto que as voltadas à orientação para pesquisa são em número marcadamente superior. Passam a fazer parte dos currículos regulares, disciplinas quanto ao agronegócio, ao meio ambiente, à biodiversidade e à questão energética.

É oportuno registrar que nos cursos implantados nos anos 1970, a presença de disciplinas da área de arquitetura e urbanismo era marcante e todos tinham não só no título a referência ao urbano como também a composição curricular era voltada ao estudo e ao planejamento metropolitano. As questóes regionais, quando tratadas o eram sob a perspectiva das desigualdades entre as macrorregiōes brasileiras.

As dissertações são o mais importante produto de um programa de mestrado. No caso específico em análise apenas um desses cursos apresenta um número significativo de dissertaçôes defendidas, pois os demais, por serem relativamente novos, apresentam resultados ainda modestos. Entretanto, por sua própria proposição original, os programas de mestrados profissionais têm um papel a cumprir perante as regiốes em que se localizam, o que os diferencia dos mestrados acadêmicos. Deles, outras modalidades de "produtos" poderiam ser esperados, tais como a divulgação de boletins sobre problemas que afetem a região; série de textos voltados à análise regional, ou alguma outra forma de tornar pública a produção de seus docentes e discentes. Ou seja, neste item a indagação levantada foi: os cursos dessa modalidade já vêm buscando organizar veículos próprios para a divulgação de sua produção técnico-científica como forma de estreitar os vínculos com as regiôes e cidades onde operam?

O que foi apurado é que apenas um deles vem desde 2003 publicando um boletim trimestral com objetivo de difundir e promover o debate sobre as rendas petrolíferas e mantém ainda em operaçáo um banco de dados que disponibiliza informaçôes sobre a distribuição dos royalties e participação especiais, uma das mais importantes questôes que afetam a região em que o Programa se localiza.

Dada a reconhecida dificuldade de elaboração e manutenção de periódicos de qualidade, os coordenadores, em fevereiro de 2012, tomaram a decisão de propor a implantação de uma revista sob a responsabilidade do coletivo dos programas e que fosse voltada à difusão do conhecimento científico quanto ao planejamento e ao desenvolvimento econômico e social em suas dimensóes regionais e urbanas. Essa proposta está em processo de concretização com a publicação da Revista Brasileira de Planejamento e Desenvolvimento, cujo primeiro número veio a público em dezembro de 2012. 


\section{CONCLUINDO}

No nosso entendimento a querela em torno dos MP está superada. Em um mundo onde a capacitação profissional é o requisito básico para a entrada no mercado de trabalho e diante da reconhecida baixa qualificação que o ensino de segundo e terceiro grau vêm proporcionando à população brasileira, toda iniciativa de ampliar as possibilidades de formação melhor qualificada deve ser saudada.

Nesse sentido, conforme acentua Ribeiro (2005, p. 10), "numa sociedade em que o conhecimento é cada vez mais importante, é imperioso a pós-graduação assumir a formação dos profissionais que atendam essa demanda."

Assim sendo, os Mestrados Profissionais têm um enorme papel a cumprir além do mundo da produção, levando a um público mais amplo, meios e modos de atuar contra a miséria e a iniquidade e, desse modo, ser um dos agentes para o resgate da dívida social. Claro está que ambas vertentes são importantes, a primeira para nosso desenvolvimento econômico, a segunda para o desenvolvimento social.

São claras as transformaçôes pelas quais a área passou em termos de composição curricular, campos de atuação, formação docente e localização. Enquanto os primeiros programas da área são voltados ao planejamento urbano-metropolitano, na virada do século esse padrão irá mudar. Os novos cursos trazem a temática do desenvolvimento regional, agora tratado não mais sob a perspectiva dos desequilíbrios entre as macrorregióes brasileiras (Norte, Nordeste, Sudeste, Sul e Centro-Oeste), mas sim focado em regiōes delimitadas do interior do país ou sobre a problemática das regiôes metropolitanas de segundo nível.

Nesses cursos, de orientação regional mais nítida, observa-se a interlocução mais próxima com áreas de conhecimento tais como Administração de Empresas, Engenharia da Produção, Economia, Geografia, Ciências Agrárias, Meio Ambiente. O desafio de aceitar essa variedade de abordagens disciplinares e metodológicas é reconhecer e tratar tais diferenças sem gerar perdas teóricas ou cair em casuísmos. Esse desafio inclui, também, a superação de generalizaçôes que pouco avançam no conhecimento da diversidade que caracteriza o país.

Sem dúvida, cada vez mais, a sociedade brasileira requer ser melhor conhecida, o que dependerá da promoção de estudos, pesquisas e debates, entre especialistas e atores políticos, centrados na construção de um futuro socialmente mais justo e territorialmente menos desigual. Na construção desse futuro, os mestrados profissionais muito terão a contribuir.

\section{REFERÊNCIAS BIBLIOGRÁFICAS}

AGOPYAN, V.; OLIVEIRA, J.F.G. Mestrado profissional em Engenharia: uma oportunidade para incrementar a inovaçáo colaborativa entre universidades e os setores de produçáo no Brasil. Revista Brasileira de Pós-Graduação, Brasília, v. 2, n. 4, p. 79-89, jul. 2005.

BRANDÁO, C.A. A Busca da Utopia do Planejamento Regional. Revista Paranaense de Desenvolvimento, Curitiba, n. 120, p. 11-31, jan./jun. 2011.

CAPES. A necessidade de desenvolvimento da pós-graduação profissional e o ajustamento do Sistema de Avaliação às características desse segmento. Boletim da Capes, dez. 2001.

. Parecer CNE/CES 0079/2002.
Rosélia Piquet é doutora em Economia pela Universidade Federal do Rio de Janeiro (UFRJ); coordenadora do Mestrado Profissional em Planejamento Regional e Gestão de Cidades da Universidade Candido Mendes (UCAM) - Campos; bolsista de produtividade do ConseIho Nacional de Desenvolvimento Científico e Tecnológico (CNPq), Brasil. E-mail: ropiquet@terra.com.br.

Rodrigo Machado Vilani é doutor em Meio Ambiente pela Universidade do Estado do Rio de Janeiro (UERJ); professor adjunto do Mestrado em Planejamento Regional e Gestão de Cidades da Universidade Candido Mendes (UCAM) - Campos, Brasil. Email: r_vilani@yahoo.com.br. 
Documento de Área Interdisciplinar: Triênio 2007-2009. Brasília: CAPES, abril de 2008.

Cursos recomendados e reconhecidos. Disponível em: <http://www.capes.gov.br/avaliacao/cursos-recomendados-e-reconhecidos>. Acesso em: 03 maio 2012.

CASTRO, C. M. A hora do mestrado profissional. In: Revista Brasileira de Pós-graduação, v. 2, n. 4. 2005. p. 16-23.

GEOCAPES. Distribuição de programas de pós-graduação no Brasil. Disponível em: <http:// geocapes.capes.gov.br/geocapesds/\#app=c501\&da7a-selectedIndex=0\&5317-selectedIndex=0\&dbcb-selectedIndex=0 >. Acesso em: 03 maio 2012.

NEGRET, F. A Identidade e a importância dos mestrados profissionais no Brasil e algumas consideraçôes para a sua avaliação. Revista Brasileira de Pós-Graduação, Brasília, v. 5, n. 10, p. 217-225, dez./2008.

RIBEIRO, R. J. O mestrado profissional na política atual da Capes. Revista Brasileira de PósGraduação, Brasília, v. 2, n. 4, p. 8-15, jul. 2005.

SILVEIRA, V.O.; PINTO, F.C.S. Reflexões necessárias sobre o mestrado profissional. Revista Brasileira de Pós-Graduação, Brasília, v. 2, n. 4, p. 38-47, jul. 2005.

VELOSO, J. Mestres e doutores no Brasil: destinos profissionais e políticas de pós-graduação. Cadernos de Pesquisa, v. 34, n. 123, p. 583-611, set./dez. 2004.

A B S T R A C T The current article's purpose is to present the challenges and contributions of the professional masters in the Brazilian post-graduation. Although, this modality has been previewed since its idealization in 1950, the implementation of masters due to professional formation has suffered disapproval throughout its execution in Brazil. The study analyses the CAPES (it is a government agency linked with the Brazilian Education Ministry, in charge of promoting high standards for post-graduation courses in Brazil) requirements related to the professional masters recognition and the development of its data since 2000, particularly in the area of Urban and Regional Policy. Looking forward to concluding, it is mentioned general and specific considerations due to the importance of professional masters in the range of national post-graduations, forming qualified professionals to develop an adequate reading and to put forward positive solutions to build a single and egalitarian society to close and future generation.

K E Y W O R D S Professional Masters. Urban and Regional Policy. CAPES. Professional Qualification. 